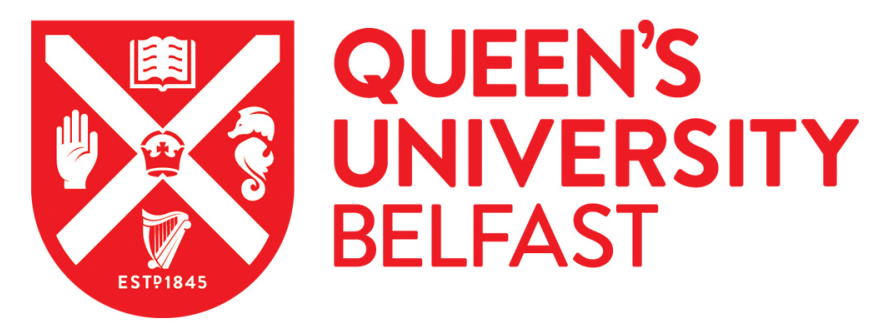

\title{
Hypopharyngeal and distal esophageal ph monitoring in children with gastroesophageal reflux and respiratory symptoms
}

Ramaiah, R. N., Stevenson, M., \& McCallion, W. A. (2005). Hypopharyngeal and distal esophageal ph monitoring in children with gastroesophageal reflux and respiratory symptoms. Journal of Pediatric Surgery, 40(10), 1557-1561. https://doi.org/10.1016/j.jpedsurg.2005.06.026

Published in:

Journal of Pediatric Surgery

Queen's University Belfast - Research Portal:

Link to publication record in Queen's University Belfast Research Portal

\section{General rights}

Copyright for the publications made accessible via the Queen's University Belfast Research Portal is retained by the author(s) and / or other copyright owners and it is a condition of accessing these publications that users recognise and abide by the legal requirements associated with these rights.

Take down policy

The Research Portal is Queen's institutional repository that provides access to Queen's research output. Every effort has been made to ensure that content in the Research Portal does not infringe any person's rights, or applicable UK laws. If you discover content in the Research Portal that you believe breaches copyright or violates any law, please contact openaccess@qub.ac.uk. 


\title{
Hypopharyngeal and distal esophageal pH monitoring in children with gastroesophageal reflux and respiratory symptoms
}

\author{
Raghu N. Ramaiah ${ }^{a}$, Michael Stevenson ${ }^{b}$, William A. McCallion ${ }^{a, *}$ \\ ${ }^{a}$ Department of Paediatric Surgery, Royal Belfast Hospital for Sick Children, Belfast BT12 6BE, Northern Ireland \\ ${ }^{\mathrm{b}}$ Department of Epidemiology, The Queen's University of Belfast, Belfast BT12 6BA, Northern Ireland
}

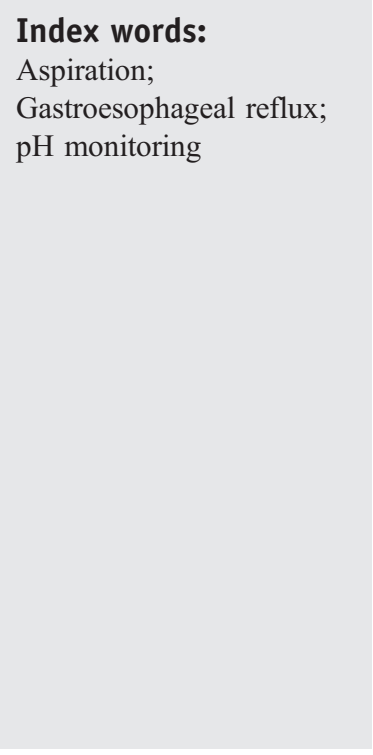

\begin{abstract}
Purpose: Fundoplication is frequently required for gastroesophageal reflux (GER)-related respiratory disease. Correlation between esophageal $\mathrm{pH}$ data and respiratory symptoms is poor but may be improved by monitoring hypopharyngeal $\mathrm{pH}$. Reflux to the hypopharynx is underestimated by salivary bicarbonate. The aim of this study was to determine if hypopharyngeal $\mathrm{pH}$ monitoring using $\mathrm{pH} 4$ and $\mathrm{pH} 5$ as reflux thresholds could predict children with reflux-related respiratory disease.

Methods: One hundred five children aged 4 months to 12 years underwent esophageal and hypopharyngeal $\mathrm{pH}$ monitoring. Hypopharyngeal $\mathrm{pH}$ data were analyzed using $\mathrm{pH} 4$ and $\mathrm{pH} 5$ as reflux thresholds. $\mathrm{pH}$ data from 4 groups were compared: group A, control group, no GER, no respiratory symptoms $(n=20)$; group $B$, respiratory symptoms, no GER $(n=16)$; group $C$, GER, no respiratory symptoms $(\mathrm{n}=26)$; and group $\mathrm{D}$, both GER and respiratory symptoms $(\mathrm{n}=37)$.

Results: Comparing groups $\mathrm{C}$ and $\mathrm{D}$, there was no significant difference in hypopharyngeal $\mathrm{pH}$ data. Using $\mathrm{pH} 5$ as the reflux threshold, children in group B refluxed to the hypopharynx significantly more frequently than controls. This was most evident in children with wheeze.

Conclusion: Hypopharyngeal $\mathrm{pH}$ monitoring does not differentiate children with GER and respiratory symptoms from those with GER alone and is therefore of doubtful value in diagnosing recurrent aspiration.

(C) 2005 Elsevier Inc. All rights reserved.
\end{abstract}

Gastroesophageal reflux (GER) is frequently associated with respiratory symptoms [1]. Respiratory symptoms may be induced by aspiration of refluxed gastric contents or by reflex vagus nerve-mediated bronchospasm or laryngospasm [2]. Primary respiratory disease can cause secondary GER [3]. Therefore, proving cause and effect is difficult.

\footnotetext{
* Corresponding author. Tel.: +44 2890632004; fax: +44 2890235340

E-mail address: bill.mccallion@royalhospitals.n-i.nhs.uk (W.A. McCallion).
}

Investigations aimed at proving the association between GER and respiratory symptoms include fluoroscopic contrast studies, technetium scintiscanning, and the detection of lipid in alveolar macrophages in bronchoalveolar lavage fluid. The specificity of the latter is reported to be as low as $57 \%$ [4], whereas contrast studies and scintigraphy have low sensitivity [5]. Prolonged intraesophageal $\mathrm{pH}$ monitoring is widely regarded as the gold standard for diagnosing GER. The use of $\mathrm{pH}$ monitoring has been extensively validated in children $[6,7]$, and its reproducibility is ensured $[8,9]$. Furthermore, pediatric age-related control data are available [10]. Although 
$\mathrm{pH}$ monitoring can provide a temporal relationship between intraesophageal acid exposure and respiratory symptoms, it cannot distinguish aspiration from reflex vagus nervemediated airway constriction. Prolonged measurement of hypopharyngeal $\mathrm{pH}$ has demonstrated extraesophageal reflux in children with a variety of upper and lower respiratory symptoms $[11,12]$. However, using the traditional definition of an acid reflux episode as a reduction in intraluminal $\mathrm{pH}$ to less than 4 may underestimate hypopharyngeal reflux owing to the neutralizing effect of salivary bicarbonate. In a small study of simultaneous esophageal and tracheal $\mathrm{pH}$ in adults, a reduction in tracheal $\mathrm{pH}$ to 5 correlated with alteration in respiratory function [13].

By recruiting patients presenting primarily with signs and symptoms suggesting GER, the aim of this study was to determine if the presence and severity of concomitant respiratory symptoms could be predicted by prolonged measurement of hypopharyngeal $\mathrm{pH}$ using both $\mathrm{pH} 4$ and $\mathrm{pH} 5$ as reflux thresholds.

\section{Materials and methods}

\subsection{Patient sample}

One hundred five patients aged 4 months to 12 years presenting with symptoms suggestive of gastroesophageal reflux disease were recruited to the study. These symptoms included recurrent vomiting or regurgitation, retrosternal or epigastric pain, excessive irritability in relation to feeds, or frequent feed refusal. A history of apnea, recurrent cough, choking, stridor, wheeze, or pneumonia was sought, and any temporal relationship between respiratory and reflux symptoms was determined. In addition, a history of developmental delay was noted.

Respiratory symptoms were graded as follows:

$$
\begin{aligned}
0= & \text { none; } \\
1= & \text { infrequent }(<1 \text { episode daily), life-style unaffected; } \\
2= & \text { frequent (daily), life-style unaffected; and } \\
3 & =\text { life-style affected and/or respiratory symptoms } \\
& \text { requiring hospital admission. }
\end{aligned}
$$

\section{2. $\mathrm{pH}$ monitoring}

$\mathrm{pH}$ monitoring was performed using 2 Synectics semidisposable monocrystant antimony $\mathrm{pH}$ electrodes. The electrodes were placed under general anesthesia at the time of endoscopy, a technique previously validated by the senior author [9]. The distal electrode was passed to a distance $13 \%$ of the esophageal length above the cardioesophageal junction [14]. The proximal $\mathrm{pH}$ electrode was placed in the hypopharynx, under direct vision, adjacent to the laryngeal inlet. Silver/silver chloride cutaneous reference electrodes were used. $\mathrm{pH}$ data were recorded on a Synectics Digitrapper Mark III (Synetics Medical Ltd, Middlesex, England) and analyzed using "EsopHogram" (Gastrosoft Inc, Stockholm, Sweden). The electrodes were tested before and after each recording in Synectics buffers of $\mathrm{pH} 7$ and $\mathrm{pH} 1$. None were discarded because of excessive drift ( $>0.2 \mathrm{pH}$ units), but 6 studies were excluded from further analysis because reduction in hypopharyngeal $\mathrm{pH}$ was not associated with concomitant reduction in distal esophageal $\mathrm{pH}$. The minimum duration of $\mathrm{pH}$ study was 18 hours. During the study, the patient was fed a bland diet every 4 hours.

Four reflux parameters were used to determine distal esophageal acid exposure, each using $\mathrm{pH} 4$ as the reflux threshold:

1. percentage of time during which $\mathrm{pH}$ was less than 4 ,

2. number of reflux episodes per hour,

3. number of reflux episodes lasting longer than 5 minutes, and

4. duration of the longest reflux episode.

Eight reflux parameters were used to determine hypopharyngeal acid exposure, 4 using $\mathrm{pH} 4$ as the reflux threshold and 4 using pH 5 as the reflux threshold: percentage of time during which $\mathrm{pH}$ was less than the reflux threshold, number of reflux episodes per hour, number of reflux episodes lasting longer than 5 minutes, and duration of the longest reflux episode.

Thirty-six patients had distal esophageal $\mathrm{pH}$ data within the reference range for age. The remaining 63 had abnormal data indicating significant GER.

\subsection{Groups for comparison}

Patients were categorized into 4 groups based on 2 factors, respiratory symptoms and the presence or absence of GER as

\begin{tabular}{|c|c|c|c|c|c|c|c|c|c|c|}
\hline \multirow[t]{2}{*}{ Group } & \multirow[t]{2}{*}{$\mathrm{n}$} & \multirow[t]{2}{*}{ Apnea } & \multirow[t]{2}{*}{ Cough } & \multirow[t]{2}{*}{ Choking } & \multirow[t]{2}{*}{ Wheeze } & \multirow[t]{2}{*}{ Pneumonia } & \multicolumn{4}{|c|}{ Respiratory score } \\
\hline & & & & & & & 0 & 1 & 2 & 3 \\
\hline A & 20 & 0 & 0 & 0 & 0 & 0 & 20 & 0 & 0 & 0 \\
\hline B & 16 & 2 & 13 & 8 & 8 & 10 & 0 & 6 & 3 & 7 \\
\hline $\mathrm{C}$ & 26 & 0 & 0 & 0 & 0 & 0 & 26 & 0 & 0 & 0 \\
\hline $\mathrm{D}$ & 37 & 9 & 30 & 11 & 24 & 15 & 0 & 9 & 9 & 19 \\
\hline
\end{tabular}
determined by distal esophageal $\mathrm{pH}$ data (Table 1):

Group A $(\mathrm{n}=20)$ : no respiratory symptoms, no GER (controls);

Table 1 Patient groups based on respiratory history and distal esophageal reflux data 
Table 2 Distal esophageal $\mathrm{pH}$ data (mean with SD in parentheses)

\begin{tabular}{lllll}
\hline Distal esophageal $\mathrm{pH}$ data & Group A $(\mathrm{n}=20)$ & Group B $(\mathrm{n}=16)$ & Group C $(\mathrm{n}=26)$ & Group D $(\mathrm{n}=37)$ \\
\hline$\% \mathrm{pH}<4$ & $1.5(1.2)$ & $1.9(1.3)$ & $14.5(10.8)$ & $15.9(12.9)$ \\
Reflux episodes per $\mathrm{h}$ & $1.1(0.7)$ & $1.4(1.5)$ & $2.4(2.0)$ & $2.4(1.3)$ \\
Reflux episodes $>5 \mathrm{~min}$ & $0.5(1.1)$ & $0.4(0.7)$ & $6.6(4.3)$ & $6.5(4.5)$ \\
Longest reflux episode $(\mathrm{min})$ & $4.8(4.9)$ & $5.6(6.5)$ & $40.3(36.8)$ & $55.0(47.6)$ \\
\hline
\end{tabular}

Group B $(n=16)$ : respiratory symptoms, no GER; Group C $(n=26)$ : no respiratory symptoms, GER diagnosed; and

Group D ( $\mathrm{n}=37)$ : respiratory symptoms; GER diagnosed.

\subsection{Statistical analysis}

The study design was an observational 2 by 2 factorial with particular comparisons of interest being between groups $\mathrm{A}$ and $\mathrm{B}$ and between groups $\mathrm{C}$ and $\mathrm{D}$. For reasons of unequal variance, the univariate analysis was based on nonparametric Mann-Whitney $U$ test. Logistic regression was used to analyze hypopharyngeal $\mathrm{pH}$ data as outcome variables, with apnea, choking, wheeze, pneumonia, and developmental delay as explanatory variables.

The study was approved by the Research Ethics Committee of the Queen's University of Belfast. Written informed parental consent was obtained in each case.

\section{Results}

Distal esophageal $\mathrm{pH}$ data are shown in Table 2. Comparing groups $\mathrm{A}$ and $\mathrm{B}$ where distal esophageal $\mathrm{pH}$ data were within the reference range, there was no difference in any of the reflux parameters between patients with respiratory symptoms (group B) and those without (group A). Similarly, in the comparison of groups $\mathrm{C}$ and $\mathrm{D}$, where distal esophageal $\mathrm{pH}$ data indicated GER, there was no significant difference between patients with concomitant respiratory disease (group D) and those with GER alone (group C).

Hypopharyngeal $\mathrm{pH}$ data using $\mathrm{pH} 4$ as the reflux threshold are shown in Table 3. Group A patients (controls) refluxed on average 0.2 times per hour to the hypopharynx compared with 0.9 times per hour for those with respiratory symptoms and normal distal esophageal $\mathrm{pH}$ data (group B). However, this difference did not reach statistical signifi- cance $(P=.08)$. The percentage time that hypopharyngeal $\mathrm{pH}$ was less than 4 was $0.3 \%$ for control group A compared with $0.8 \%$ for group B. This, too, failed to reach statistical significance $(P=.35)$. Similarly, there was no difference in the number of reflux episodes lasting longer than 5 minutes or the longest reflux episode between groups $\mathrm{A}$ and B. Of the patients with GER defined by distal esophageal $\mathrm{pH}$ data, there was no significant difference in any of the 4 parameters of hypopharyngeal reflux using $\mathrm{pH} 4$ as the reflux threshold in patients with GER alone (group C) compared with those with both GER and respiratory disease (group D).

Hypopharyngeal $\mathrm{pH}$ data using $\mathrm{pH} 5$ as the reflux threshold are shown in Table 4. Patients in group B, those with respiratory symptoms and normal distal esophageal $\mathrm{pH}$ data, recorded, on average, 3.9 reflux episodes per hour compared with 0.6 episodes per hour for group A patients. This difference reached statistical significance $(P=.035)$. The percentage of time that hypopharyngeal $\mathrm{pH}$ was less than 5 was $1.8 \%$ for group B compared with $0.5 \%$ for group A. This, too, reached statistical significance ( $P=.019)$. However, there was no difference in the number of reflux episodes lasting longer than 5 minutes or the longest reflux episode between groups A and $\mathrm{B}$ using $\mathrm{pH} 5$ as the reflux threshold. Further analysis of hypopharyngeal reflux episodes per hour (using pH 5 as the reflux threshold) revealed a dichotomized U-shaped distribution with 1 or less or 2 or more reflux episodes per hour. With individual respiratory symptoms and the presence of developmental delay as explanatory variables and the dichotomy of reflux episodes per hour as the outcome variable in a logistic regression equation, using stepwise backward elimination, the only explanatory variable which correlated significantly with hypopharyngeal reflux was wheeze.

Of the patients with GER defined by distal esophageal $\mathrm{pH}$ data, there was no significant difference in any of the 4 parameters of hypopharyngeal reflux using $\mathrm{pH} 5$ as the reflux threshold in patients with GER alone (group C)

Table 3 Hypopharyngeal $\mathrm{pH}$ data using $\mathrm{pH} 4$ as the reflux threshold (mean with $\mathrm{SD}$ in parentheses)

\begin{tabular}{lllll}
\hline Hypopharyngeal $\mathrm{pH}$ data & Group A $(\mathrm{n}=20)$ & Group B $(\mathrm{n}=16)$ & Group C $(\mathrm{n}=26)$ & Group D $(\mathrm{n}=37)$ \\
\hline$\% \mathrm{pH}<4$ & $0.3(0.5)$ & $0.8(1.5)$ & $1.9(1.5)$ & $2.2(3.5)$ \\
Reflux episodes per h & $0.2(0.2)$ & $0.9(2.0)$ & $0.7(1.1)$ & $0.7(1.0)$ \\
Reflux episodes $>5$ min & $0.2(0.5)$ & $0.2(0.6)$ & $1.2(1.4)$ & $0.9(1.4)$ \\
Longest reflux episode (min) & $1.7(3.4)$ & $2.5(3.6)$ & $7.2(7.4)$ & $12.0(21.7)$ \\
\hline
\end{tabular}


Table 4 Hypopharyngeal pH data using pH 5 as the reflux threshold (mean with SD in parentheses)

\begin{tabular}{lllcc}
\hline Hypopharyngeal $\mathrm{pH}$ data & Group A $(\mathrm{n}=20)$ & Group B $(\mathrm{n}=16)$ & Group C $(\mathrm{n}=26)$ & Group D $(\mathrm{n}=37)$ \\
\hline$\% \mathrm{pH}<5$ & $0.5(0.7)$ & $1.8(2.0)$ & $5.0(4.6)$ & $4.7(5.7)$ \\
Reflux episodes per $\mathrm{h}$ & $0.6(0.6)$ & $3.9(4.0)$ & $3.4(3.9)$ & $3.7(3.7)$ \\
Reflux episodes $>5 \mathrm{~min}$ & $0.2(0.6)$ & $0.3(0.7)$ & $2.1(2.9)$ & $1.5(2.5)$ \\
Longest reflux episode $(\mathrm{min})$ & $2.4(4.4)$ & $4.4(9.1)$ & $11.7(13.2)$ & $19.6(33.8)$ \\
\hline
\end{tabular}

compared with those with both GER and respiratory disease (group D).

\section{Discussion}

Fundoplication, which is one of the 3 most commonly performed major operations on children [15], is often performed for reflux-related respiratory disease [16]. However, correlation between the severity of GER, as determined by distal esophageal $\mathrm{pH}$ monitoring, and respiratory function is poor [17]. Synchronous recording of distal and proximal esophageal $\mathrm{pH}$ has been reported in asthmatic children [18], although this does not take into account the competence of the upper esophageal sphincter. By simultaneously monitoring distal esophageal and hypopharyngeal $\mathrm{pH}$, a record is obtained of gastric acid reaching the laryngeal inlet. In this study, simultaneous distal esophageal and hypopharyngeal $\mathrm{pH}$ monitoring was used in a cohort of patients presenting primarily with reflux symptoms to correlate the presence and severity of respiratory symptoms with hypopharyngeal $\mathrm{pH}$ data. Using the traditional reflux threshold of $\mathrm{pH} \mathrm{4}$, data from the hypopharyngeal electrode failed to distinguish children with respiratory symptoms from those without. In a similar study by Little et al [11], distal esophageal and hypopharyngeal $\mathrm{pH}$ monitoring was performed on 222 children presenting primarily with respiratory symptoms. These authors concluded that, in the presence of respiratory symptoms, any reflux to the hypopharynx was significant even when distal esophageal $\mathrm{pH}$ data were within the reference range. This is not borne out by the present study. Hypopharyngeal reflux appears to be a physiological event during childhood given that subjects from control group A refluxed to the hypopharynx on average of 0.2 times per hour (Table 3 ). In addition, there was no significant difference in hypopharyngeal data from children with respiratory symptoms (groups B and D) compared with those with GER alone (Table 3). Hypopharyngeal $\mathrm{pH}$ monitoring using the reflux threshold of $\mathrm{pH} 4$ is of limited value in identifying children with aspirationrelated respiratory disease.

To compensate for the neutralizing effect of salivary bicarbonate, hypopharyngeal data were reanalyzed using $\mathrm{pH}$ 5 as the reflux threshold. This is in line with the findings of Jack et al [13] who detected gastric acid in the trachea with $\mathrm{pH}$ up to 5. However, increasing the threshold $\mathrm{pH}$ at the hypopharyngeal electrode from 4 to 5 still did not differentiate children with GER and respiratory symptoms (group D) from those with GER alone (group C). Indeed, children in group $\mathrm{C}$ (ie, those without respiratory symptoms) refluxed to the hypopharynx on average of 3.4 times per hour. This supports the conclusions reached by Hampton et al [17] that host mechanisms such as the competence of the laryngeal inlet may be more important determinants of aspiration rather than the "quantity" of gastric acid refluxed to the hypopharynx. In the presence of a competent laryngeal inlet, repeated reflux episodes to the hypopharynx will not result in aspiration.

When the hypopharyngeal $\mathrm{pH}$ data of groups $\mathrm{A}$ and $\mathrm{B}$ (ie, those with normal distal esophageal $\mathrm{pH}$ monitoring) were analyzed using pH 5 as the reflux threshold, children with respiratory symptoms (group B) had significantly greater hypopharyngeal acid exposure, averaging 3.9 reflux episodes per hour, than those in group A who averaged 0.6 reflux episodes per hour. Using logistic regression, this increased hypopharyngeal acid exposure was found particularly in wheezing children. Whether hypopharyngeal reflux in this group of children resulted in "silent" aspiration and bronchospasm or whether the wheeze was the primary event inducing secondary reflux to the hypopharynx remains unanswered. Although, it is noteworthy that children in group B refluxed to the hypopharynx as often as those in group $\mathrm{C}$ who had GER but no respiratory symptoms (3.9 and 3.4 reflux episodes per hour, respectively). One explanation for this is that the presence of wheeze has induced secondary reflux to the hypopharynx, but this reflux has not been sufficiently severe to make distal esophageal $\mathrm{pH}$ data abnormal.

The prolonged measurement of hypopharyngeal $\mathrm{pH}$ in children presenting with reflux symptoms does not help identify children at risk for aspiration-related respiratory disease. The latter is more likely to be owing to host factors such as effectiveness of pharyngeal clearance or competence of the laryngeal inlet rather than the "quantity" of gastric acid refluxed to the hypopharynx. Children with respiratory symptoms, wheeze in particular, but whose distal esophageal $\mathrm{pH}$ data are normal may induce secondary reflux to the hypopharynx. However, synchronous distal esophageal and hypopharyngeal $\mathrm{pH}$ monitoring cannot distinguish, with certainty, the chicken from the egg.

\section{References}

[1] Andze GO, Brandt ML, St Vil D, et al. Diagnosis and treatment of gastroesophageal reflux in 500 children with respiratory symptoms: the value of pH monitoring. J Pediatr Surg 1991;26:295-300. 
[2] Wilson NM, Charette L, Thomson AH, et al. Gastro-oesophageal reflux and childhood asthma: the acid test. Thorax 1985;40:592-7.

[3] Singh V, Jain NK. Asthma as a cause for rather than a result of, gastroesophageal reflux. J Asthma 1983;20:241 -3.

[4] Corwin RW, Irwin RS. The lipid-laden macrophage as a marker of aspiration in parenchymal lung disease. Am Rev Respir Dis 1985; 132:576-81.

[5] Ruth M, Carlsson S, Mansson I, et al. Scintigraphic detection of gastro-pulmonary aspiration in patients with respiratory disorders. Clin Physiol 1993;13:19-33.

[6] Boix-Ochoa J, Lafuente JM, Gil-Vernet JM. Twenty-four hour esophageal $\mathrm{pH}$ monitoring in gastroesophageal reflux. J Pediatr Surg 1980;15:74-8.

[7] Evans DF, Robertson CS, Ledingham SJ, et al. Esophageal pH monitoring for gastroesophageal reflux: a United Kingdom study. J Pediatr Surg 1991;26:682-5.

[8] Vandenplas Y, Helven R, Goyvaerts H, et al. Reproducibility of continuous 24 hour oesophageal $\mathrm{pH}$ monitoring in infants and children. Gut 1990;31:374-7.

[9] McCallion WA, Gallagher TM, Boston VE, et al. Effect of general anaesthesia on prolonged intraoesophageal $\mathrm{pH}$ monitoring. Arch Dis Child 1995;73:235-8

[10] Vandenplas Y, Sacre L. Continuous 24-hour esophageal pH monitoring in 285 asymptomatic infants $0-15$ months old. J Pediatr Gastroenterol Nutr 1987;6:220-4.
[11] Little JP, Matthews BL, Glock MS, et al. Extraesophageal paediatric reflux: 24-hour double-probe $\mathrm{pH}$ monitoring of 222 children. Ann Otol Rhinol Laryngol Suppl 1997;169:1 - 16.

[12] Matthews BL, Little JP, McGuirt Jr WS, et al. Reflux in infants with laryngomalacia: results of 24-hour double-probe $\mathrm{pH}$ monitoring. Otolaryngol Head Neck Surg 1999;120:860-4

[13] Jack CI, Calverley PM, Donnelly RJ, et al. Simultaneous tracheal and oesophageal $\mathrm{pH}$ measurements in asthmatic patients with gastrooesophageal reflux. Thorax 1995;50:201-4.

[14] Strobel CT, Byrne WJ, Ament ME, et al. Correlation of oesophageal lengths in children with height: appliance of Tuttle test without prior oesophageal manometry. J Pediatr 1979;94:81 - 4.

[15] Fonkalsrud EW, Ament ME. Gastroesophageal reflux in childhood. Curr Probl Surg 1996;33:1 - 70.

[16] Fonkalsrud EW, Bustorff-Silva J, Perez CA, et al. Antireflux surgery in children under 3 months of age. J Pediatr Surg 1999;34: 527-31.

[17] Hampton FJ, MacFadyen UM, Beardsmore CS, et al. Gastrooesophageal reflux and respiratory function in infants with respiratory symptoms. Arch Dis Child 1991;66:848-53.

[18] Gustafsson PM, Kjellman NM, Tibbling L. Bronchial asthma and acid reflux into the distal and proximal oesophagus. Arch Dis Child 1990;65:1255-8 